\title{
A ASCENSÃo DA AGROPECUÁRIA E SEUS REFLEXOS SOBRE AS ESTRUTURAS SOCIOESPACIAIS DE POVOS E COMUNIDADES TRADICIONAIS NO MÉDIO SÃO FRANCISCO MINEIRO
}

\author{
Sérgio Leandro Sousa Neves ${ }^{1}$ \\ Marcos Esdras Leite ${ }^{2}$ \\ Lisa Vany Ribeiro Figueiredo Neves ${ }^{3}$
}

Resumo: Buscando compreender a dimensão e reflexos das atividades agropecuárias na socioespacialidade do Médio São Francisco mineiro, o presente estudo propõe realizar um diagnóstico e discussão sobre a expansão da atividade agropecuária, no uso e ocupação do solo nas épocas de 1986 e 2015, na região do Norte de Minas Gerais. Os procedimentos metodológicos estão pautados na construção de uma série temporal de mapas analíticos. A pesquisa concluiu que 0 avanço da agropecuária contribuiu para a emergência de impactos ambientais diversos; para a expropriação territorial e a perda de direitos dos povos e comunidades tradicionais, comprometendo a reprodução de seus modos de vida, que em contrapartida fortaleceu os movimentos sociais como estratégia de resistência aos impactos socioambientais.

Palavras-chave: Expropriação Territorial. Norte de Minas Gerais. Comunidades Tradicionais. Agronegócio.

\section{THE RISE OF AGRICULTURE AND ITS REFLEXES ON SOCIO-SPACE STRUCTURES OF PEOPLE AND TRADITIONAL COMMUNITIES IN THE MEDIUM SÃO FRANCISCO OF MINAS GERAIS}

Abstract: Aiming to understand the dimension and consequences of agricultural activities in the socio-spatiality of the Middle São Francisco of Minas Gerais, this study proposes to make a diagnosis and discussion about the expansion of agricultural activity in land use and occupation in 1986 and 2015 in the region of North of Minas Gerais. The methodological procedures are based on the construction of a time series of analytical maps. The diagnosis concluded that the advance of agriculture contributed to the emergence of various environmental impacts; It also contributed to territorial expropriation and the loss of rights of traditional peoples and communities, compromising the reproduction of their ways of life, which in turn strengthened social movements as a strategy to resist socio-environmental impacts. Keywords: Territorial Expropriation. North of Minas Gerais. Traditional Communities. Agribusiness.

\footnotetext{
${ }^{1}$ Instituto Federal do Norte de Minas Gerais - IFNMG, Diamantina-MG, Brasil, sergio.neves@ifnmg.edu.br, https://orcid.org/0000-0003-2452-0636

2 Universidade Estadual de Montes Claros - UNIMONTES, Departamento de Geociências, Montes Claros- MG, Brasil, marcosesdrasleite@gmail.com, https://orcid.org/0000-0002-9020-6445

${ }_{3}^{3}$ Universidade Estadual de Montes Claros - UNIMONTES, Departamento de Estágios e Práticas Escolares, Montes Claros- MG, Brasil, lisavany@gmail.com, https://orcid.org/0000-0001-9173-658X
} 


\section{LA ASCENSIÓN DE LA AGROPECUARIA Y SUS REFLEXIONES SOBRE LAS ESTRUCTURAS SOCIO-ESPACIALES DE LOS PUEBLOS Y COMUNIDADES TRADICIONALES DEL MEDIO SÃO FRANCISCO EN MINAS GERAIS}

Resumen: En la búsqueda por comprender la dimensión y reflexiones de las actividades agropecuarias en la socio-espacialidad del Medio São Francisco en Minas Gerais, el presente estudio propone realizar un diagnóstico y discusión sobre la expansión de la actividad agropecuaria en el uso y ocupación del suelo en los períodos de 1986 y 2015, en la región del Norte de Minas Gerais. Los procedimientos metodológicos se basan en la construcción de una serie temporal de mapas analíticos. La investigacíon concluyó que el avance de la agropecuaria contribuyó a la aparición de diversos impactos ambientales; para la expropiación territorial y la pérdida de derechos de los pueblos y comunidades tradicionales, comprometiendo la reproducción de sus formas de vida, lo que a su vez fortaleció los movimientos sociales como estrategia de resistencia a los impactos socioambientales.

Palabras clave: Expropiación territorial. Norte de Minas Gerais. Comunidades tradicionales. Agronegocio.

\section{Introdução}

Após a segunda metade do século $\mathrm{XX}$, o Brasil trilhou os caminhos da chamada modernização conservadora, a qual marcou profundamente as relações técnicas entre a agricultura e a indústria, com estímulo a adoção de pacotes tecnológicos e produção de "commodities" direcionadas ao mercado externo. As modificações promovidas por esses processos, no entanto, foram incapazes de sanar as desigualdades sociais no campo, favorecendo a preservação da estrutura fundiária existente com impactos nas estruturas socioespaciais de povos e comunidades tradicionais ${ }^{4}$.

No setor primário, com destaque para a agropecuária, o modelo de produção foi fundamentado na chamada Revolução Verde - RV e no seu pacote tecnológico, que entrelaçaram definitivamente o capitalismo com a dinâmica agrícola. Os reflexos da RV nos países subdesenvolvidos, de forma sintética, resultaram no aumento da produção de alimentos para demanda externa; dependência de insumos e equipamentos provenientes dos países desenvolvidos; degradação e contaminação dos solos por meio de técnicas impactantes; uso abusivo de agroquímicos; concentração fundiária e, principalmente, na exclusão no processo produtivo e

\footnotetext{
${ }^{4} \mathrm{O}$ termo povos e comunidades tradicionais é entendido nesse artigo como: grupos culturalmente diferenciados e que se reconhecem como tais, que possuem formas próprias de organização social, que ocupam e usam territórios e recursos naturais como condição para sua reprodução cultural, social, religiosa, ancestral e econômica, utilizando conhecimentos, inovações e práticas gerados e transmitidos pela tradição (Decreto Federal №6.040 de 7 de fevereiro de 2000). Ver: BRANDÃO e LEAL, 2012.
} 
marginalização dos povos e comunidades tradicionais, sobretudo na privatização de suas terras e recursos (NEVES, 2013).

No ano de 1965, a região Norte do Estado de Minas Gerais, foi inserida na área de abrangência das políticas públicas da Superintendência de Desenvolvimento do Nordeste - SUDENE, o que possibilitou o financiamento de linhas de crédito, através do Fundo de Investimentos do Nordeste - FINOR e do Fundo de Investimentos Setoriais - FISET, por meio de agências bancárias, que liberaram empréstimos e subsídios para implantação de projetos industriais e agropecuários, inaugurando, portanto, o processo de modernização do campo nessa região. Essa política agrícola desenvolvimentista no Norte de Minas Gerais foi orientada em quatro eixos: Agropecuário; irrigação; monocultura de eucalipto e "pinus"; e industrial. Esses eixos contribuíram para a ampliação e concentração de latifúndios e no crescimento e fortalecimento de empresas rurais, modificando, paulatinamente, a estrutura fundiária da região e/ou promovendo impactos socioambientais diversos (FEITOSA; BARBOSA, 2005).

Nesse contexto histórico, emergem as questões centrais desta pesquisa: como se configuram os processos de uso e ocupação do solo e quais os impactos advindos do modelo desenvolvimentista? Com propósito de compreender os impactos desse modelo desenvolvimentista no uso e ocupação do solo, o objetivo deste artigo é realizar um diagnóstico e discussão sobre a expansão da atividade agropecuária no uso e ocupação do solo nas épocas de 1986 e 2015, na região do Norte de Minas Gerais. Optamos por alguns municípios do médio São Francisco Mineiro como recorte geográfico, sendo eles: Pedras de Maria da Cruz, Januária, Bonito de Minas, Cônego Marinho, Itacarambi, São João das Missões, Matias Cardoso, Manga e Jaíba. Este desenho se dá devido à coexistência de um lado, por atores hegemônicos territorializantes e de outro, povos e comunidades tradicionais diversos $^{5}$, dentre eles, vazanteiros; veredeiros; caatingueiros; geraizeiros; pescadores artesanais; quilombolas e indígenas.

Estes povos, em maior ou menor intensidade, disputam territórios com distintos atores, empreendimentos e o próprio Estado. Entre eles destacamos, o Perímetro de Irrigação do Projeto Jaíba; um mosaico de áreas protegidas, composto por áreas de preservação ambiental - APA's; Refúgio de Vida Silvestre - REVIS; Unidades de Conservação - UC; o Parque Nacional Cavernas do Peruaçu - PARNA

\footnotetext{
${ }^{5}$ Ver COSTA, 2005.
} 
Peruaçu; fazendeiros e pecuaristas que, em conjunto, exercem pressão sobre as comunidades, o que tem intensificado os conflitos territoriais e ambientais.

Os interesses distintos e atuações dos diferentes atores ao longo das últimas três décadas têm contribuído para modificações espaciais que podem ser identificadas, a partir de imagens de satélite, revelando as transformações ocorridas no uso e ocupação do solo do referido recorte geográfico. Deste modo propomos avançar no seguinte questionamento: qual a dimensão e reflexos da expansão das atividades agropecuárias na socioespacialidade da região do Norte de Minas Gerais, no que tange a territorialidade dos povos e comunidades tradicionais? Importante ressaltar que este artigo não pretende sanar todas as indagações acerca da temática, mas demonstrar os resultados socioespaciais das políticas desenvolvimentistas na região.

\section{Material e Métodos}

A metodologia se pautou na análise de imagens de satélite do período pesquisado e na construção de mapas temáticos, subsidiados pela revisão bibliográfica de obras que tratam da temática das comunidades tradicionais e dinâmicas socioambientais da região do Médio São Francisco Mineiro.

A construção dos mapas se deu por meio da aquisição dos dados das imagens dos satélites Landsat/TM e Landsat/OLI, com resolução espacial de 0,9ha. As imagens foram obtidas junto ao catálogo de imagens orbitais do Instituto Nacional de Pesquisas Espaciais (INPE, 2016), cenas do ano 1986, Landsat 5 (TM) e de 2015, Landsat 8 (OLI), com a data de passagem do satélite nos meses de julho das duas épocas, tendo em vista, a menor cobertura por nuvens devido ao período de estiagem da região estudada. As órbitas/pontos foram os seguintes: 218/070, 218/071, 219/070, 219/071 e 220/070.

As bandas e as composições coloridas para o Landsat 5 consistiram em, vermelho: Banda 2; verde: Banda 3; e azul: Banda: 4. Para o Landsat 8, a seguinte seqüência, vermelho: Banda 5; verde: Banda 4; e azul: Banda 3. Estas composições foram escolhidas por demonstrarem satisfatoriamente os limites entre água e solo, e ainda, definirem razoavelmente as diferenças de vegetação (PONZONI; REZENDE, 2002; RODRIGUES et al., 2016).

Os limites municipais dos referidos municípios foram adquiridos junto ao Instituto Brasileiro de Geografia e Estatística (IBGE, 2016), em formato shapefile. Esses arquivos subsidiaram a correta localização da área de estudo. 
Os procedimentos operacionais foram realizados por meio do aplicativo computacional ArcGIS, versão 10.2.1 (ESRI, 2013), no qual desenvolveu-se etapas de pré-processamento, tais como: Composição RGB; realce e correção do contraste entre as cenas; correção do georreferenciamento e mosaico das cenas. Posteriormente com o manuseio do programa informacional para processamento digital de imagens Spring, versão 5.3 (CÂMARA et al., 1996) foi realizada a classificação das imagens, tal como poderá ser observado mais adiante (Fig. 2 e 3).

\section{Resultados e Discussão}

O Norte de Minas Gerais apresenta um mosaico de povos e comunidades tradicionais e, paralelamente, à ações hegemônicas opressoras. Essas facetas, acrescidas da realidade socioeconômica regional se imbricam, tecendo um cenário de conflitos de diversas ordens. Ressaltam-se os conflitos socioambientais que, na atualidade, dão a tônica das relações sociais e históricas na região. Os grandes empreendimentos no Norte de Minas Gerais foi desfigurando paulatinamente a paisagem, promovendo metamorfoses e rugosidades espaciais, insuflando movimentos de luta por reconhecimento, representação política pela terra e recuperação do território e das territorialidades dos expropriados durante o processo da modernização conservadora na região (FIGUEREIDO, 2011).

As comunidades e populações tradicionais dessa região podem ser categorizadas, a partir de seu domínio morfoclimático e uma inter-relação entre manejos agrícolas e modos de vida específico em destaque: Comunidades Vazanteiras, distribuídas às margens de rios com vegetação variada e territorialidades largamente influenciadas pelo ciclo das águas; Caatingueiros, localizados no sopé da Serra do Espinhaço cuja vegetação ecótona se alterna entre caatinga, cerrado e mata seca; Geraizeiros, no cerrado dos planaltos, serras, encostas e vales; Veredeiros, que desenvolvem parte da agricultura nas veredas úmidas e utilizam os planaltos do cerrados para criação de gado; Pescadores Artesanais, que vivem às margens dos rios e lagoas em especial o rio São Francisco; Quilombolas e Indígenas, povos que se estabelecem em distintos biomas da região.

Os projetos desenvolvimentistas, outrora aplicados no Norte de Minas Gerais, não consideraram esses povos e comunidades tradicionais, subjugando seus saberes, suas estruturas socioespaciais e modus operandi intrínsecas ao meio 
ambiente local, deixando o ônus dos impactos sociais e ambientais, a ser pago por essas comunidades que ao longo do tempo foram se tornando minoritárias. Com pouca representatividade política ou voz, mas empenhadas em movimentos de resistências diversos.

Ribeiro (et. al, 2010); Brito 2010 e Anaya (2014), abordam os impactos socioespaciais e culturais que incidiram sobre esses diferentes povos, no entanto, na literatura há uma lacuna a ser explorada, no que condiz, a análise da paisagem e das rugosidades espaciais produzidas pela dinâmica de uso e ocupação do solo.

Nessa perspectiva, ao analisarmos a paisagem, consideramos o conceito de espaço geográfico, a partir da concepção de Milton Santos, no qual ele é caracterizado por sua dinamicidade, como um conjunto indissociável de sistemas e objetos, naturais ou fabricados e de sistemas de ações, deliberadas ou não. Entendemos que a dinâmica existente no espaço permite a compreensão do movimento, das transformações e também das contradições, pois os objetos, no decorrer histórico, se tornam cada vez mais produtos humanos do que naturais, devido a interação e articulação com os sistemas de ações (SANTOS, 2002).

No tocante a discussão sobre espaço e as interações entre os diferentes objetos, é importante salientar a definição de Harvey (2006), que se apoia na tríade: Espaço absoluto, espaço relativo e espaço relacional. Para este autor, o espaço absoluto seria o receptáculo, o fixo, o local onde são planejados e realizados os eventos; o espaço relativo é aquele onde os fluxos atuam, é o locus da circulação, da mobilidade, da aceleração e compressão do tempo/espaço e por sua vez, o espaço relacional, que implica a ideia de relações internas, no qual, os eventos devem ser analisados, a partir da sua interação com diferentes objetos e as coisas que estão ao seu redor.

$\mathrm{Na}$ ciência geográfica não há uma definição acabada sobre os conceitos, espaço e território, portanto não nos propomos a aprofundar nessa discussão, mas por vez, se torna salutar apontar que, estes conceitos se diferem e são susceptíveis ao jogo de interações entre os sistemas de objetos, de ações, ao movimento e dinâmica histórica/temporal, fazendo com que o produto do trabalho humano exerça uma forte influência sobre os diferentes lugares e paisagens, o que contribui para a consolidação de uma divisão territorial do trabalho.

Os reflexos dessas diferentes ações sobre a paisagem, pode ser observado através das formas que o espaço vai adquirindo via trabalho humano. As formas espaciais, concebidas, são frutos do que Santos (2002) chama de "trabalho vivo e 
trabalho morto". O que pode ser visto na paisagem, portanto é reflexo de ações passadas e "nem sempre podem ser visíveis com o tempo, nem sempre é redutível aos sentidos, mas apenas ao conhecimento". Ou seja, é uma rugosidade, é "o que fica do passado com forma, espaço construído, paisagem, o que resta do processo de supressão, acumulação, superposição, com que as coisas se substituem e acumulam em todos os lugares" (SANTOS, 2002, p. 139 - 140).

As transformações, de uma dada superfície natural, por sistemas agrícolas e técnicas modernas, podem não ser visíveis num dado espaço de tempo, mas podem deixar registradas suas expressões nos lugares, ou na espacialidade, sem mesmo ser necessário existir a presença de um objeto para confirmá-las. Esses registros temporais deixados na paisagem podem ser analisados por outras ferramentas, a exemplo das imagens de satélite ou por outras tecnologias. Neste sentido, a compreensão das rugosidades espaciais, com suas formas isoladas ou arranjos, é um instrumento de análise da paisagem, enquanto categoria do espaço geográfico e ao mesmo tempo explicativa da divisão territorial do trabalho, com suas formas geográficas herdadas dentro de um enfoque espaço/temporal, nesse caso como resultado do próprio processo de modernização agrícola experimentado no Norte de Minas Gerais.

$\mathrm{Na}$ figura 1, podemos observar a espacialização de alguns dos empreendimentos que, igualmente ao agronegócio, foram responsáveis pelas alterações na dinamicidade socioespacial do recorte geográfico, que estamos analisando, bem como o ordenamento territorial decorrente das políticas públicas do Estado na mesorregião. Trata-se de um mosaico de unidades de conservação e de um grande perímetro de irrigação que utiliza, por meio de bombeamento, as águas do Rio São Francisco. 
Figura 1: Mosaico de unidades de conservação e perímetro de irrigação no médio São Francisco Mineiro
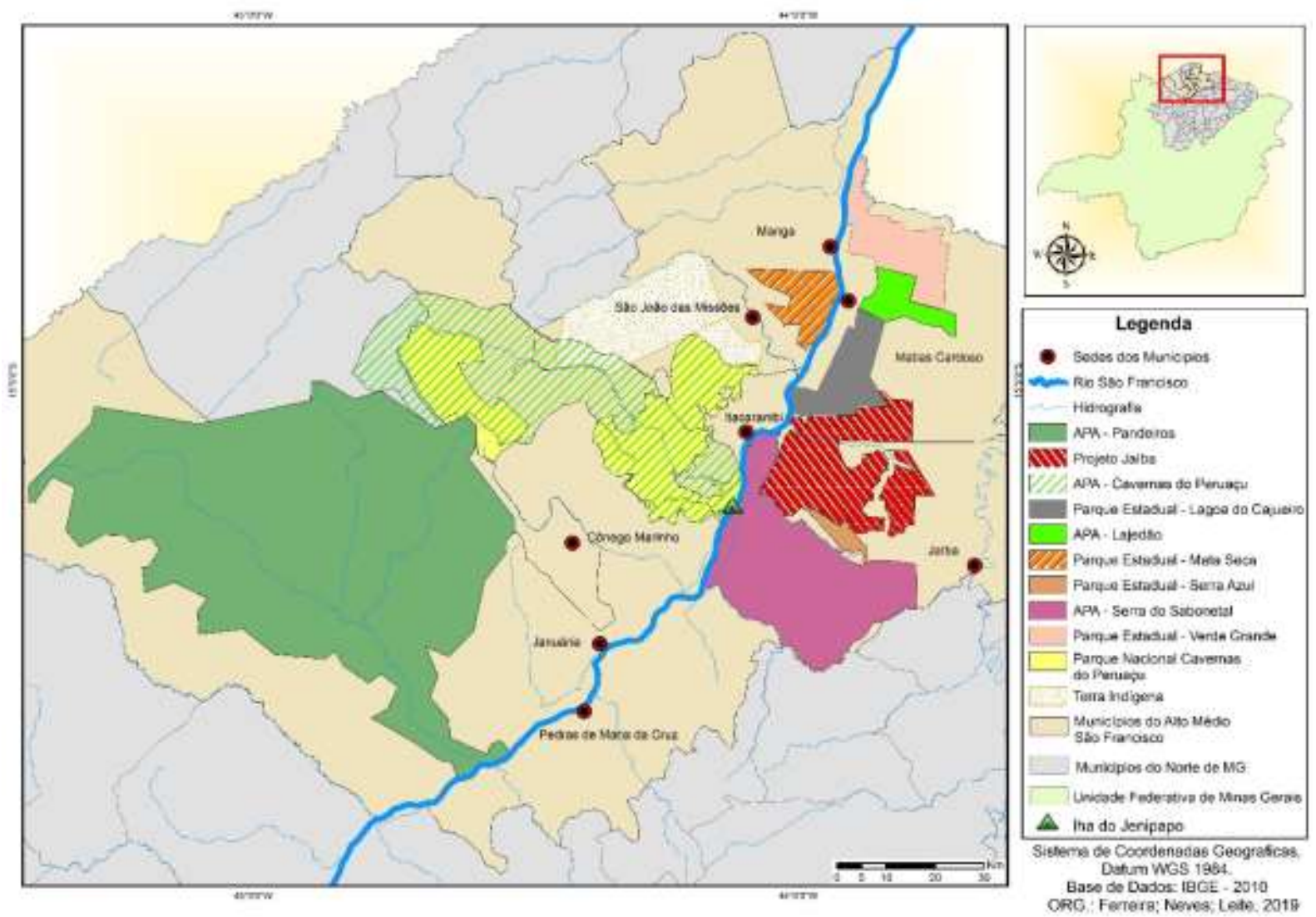

Fonte: Organizado FERREIRA, NEVES e LEITE, 2019.

Pode-se observar na figura 1, o perímetro de irrigação de fruticultura 'Projeto Jaíba'. Este empreendimento, custeado pelo governo federal e estadual, trouxe externalidades positivas para o seu entorno, em destaque algumas melhorias na área da saúde, educação, transporte e geração de emprego. Contudo, trouxe externalidades negativas, como os impactos do rápido crescimento populacional sem o devido acompanhamento da infraestrutura e aumento dos índices de violência. $\mathrm{Na}$ área ambiental, vários estudos apontam os impactos socioambientais provocados pelo empreendimento e principalmente, pelo fato do Projeto Jaíba reproduzir a estrutura fundiária brasileira e especificamente a do Norte de Minas Gerais como a alta concentração de terras (JESUS, 2009).

As unidades de conservação, por sua vez, são foco de alguns conflitos socioambientais, em especial aqueles relacionados à criação de áreas de proteção integral, que sobrepuseram territórios de povos e comunidades tradicionais diversas, dentre eles vazanteiros, geraizeiros, veredeiros, pescadores artesanais, quilombolas e indígenas (ANAYA et. aL. 2006; FIGUEIREDO, 2011). 
A partir desta perspectiva apresentada, o presente estudo objetivou através de um diagnóstico, analisar as mudanças na paisagem, a partir do uso e ocupação do solo, em duas épocas, 1986 e 2015, nos municípios, apresentados na FIG. 2 e 3, Pedras de Maria da Cruz, Januária, Bonito de Minas, Cônego Marinho, Itacarambi, São João das Missões, Matias Cardoso, Manga e Jaíba, localizados no Norte do Estado de Minas Gerais, bem como compreender o reflexo dessas atividades na socioespacialidade dos povos e comunidades tradicionais.

Figura 02: Uso do solo em municípios da região Norte do Estado de Minas Gerais no ano de 1986.

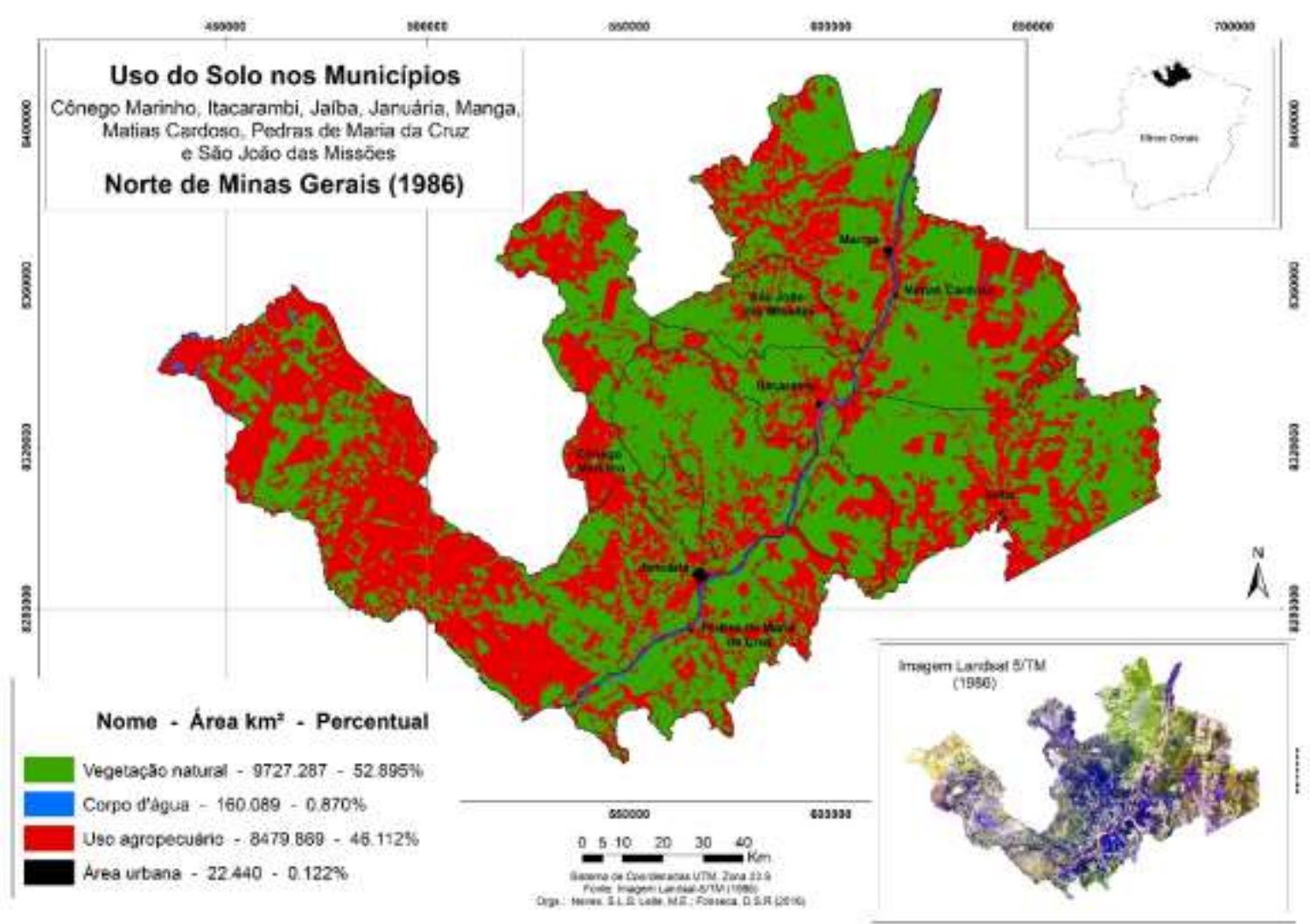

Fonte: Imagem Landsat/TM, 1986. Organizado por FONSECA, NEVES e LEITE, 2016. 
Figura 03: Uso do solo em municípios da região Norte do Estado de Minas no ano de 2015.

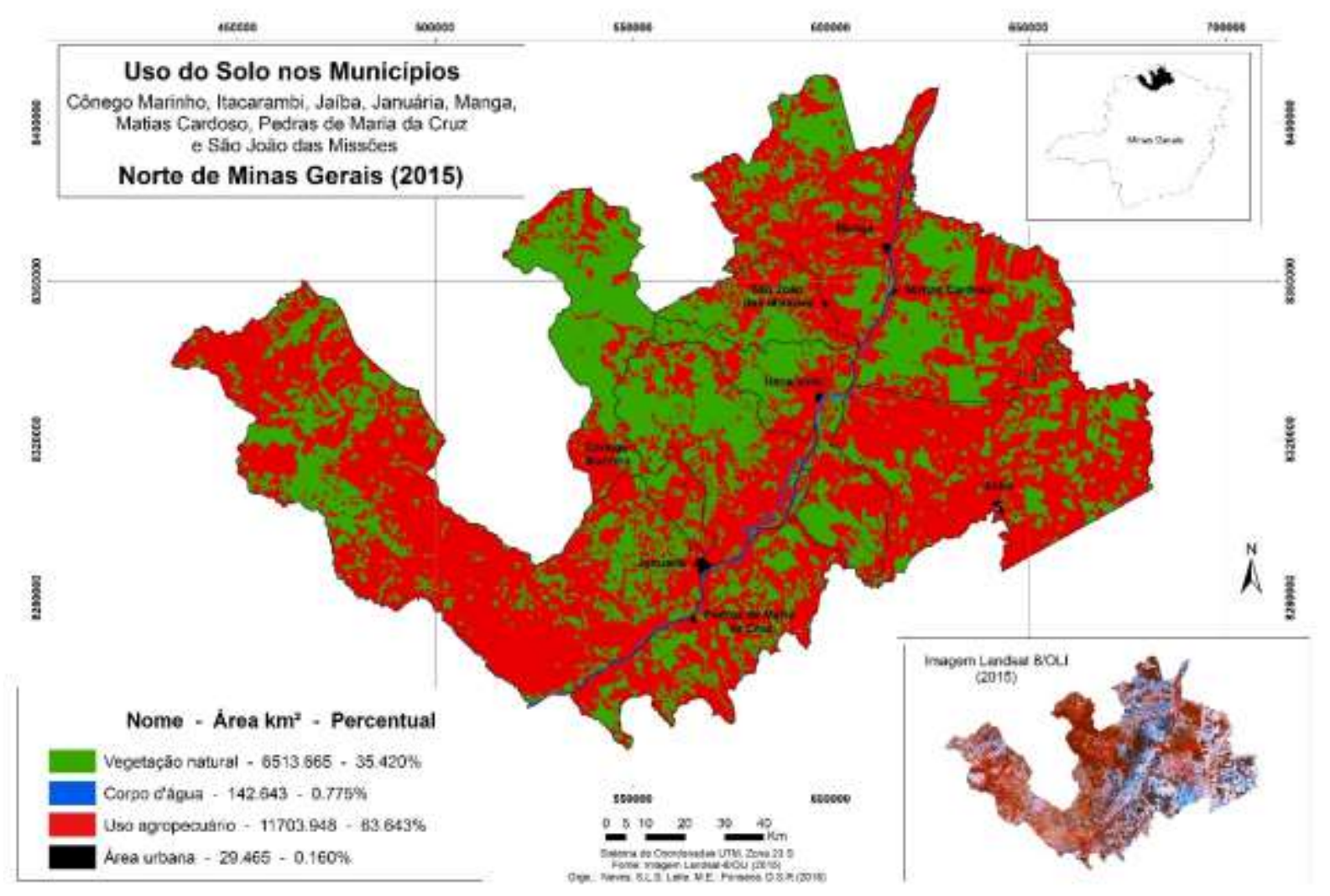

Fonte: Imagem Landsat/OLI, 2015. Organizado por FONSECA, NEVES e LEITE, 2016

A análise do uso dos solos desse recorte geográfico do Norte de Minas Gerais (1986 e 2015) permite a compreensão do avanço das atividades agropecuárias sobre as áreas de vegetação nativa. Durante este período os municípios, em destaque, perderam aproximadamente $3.213 \mathrm{~km}^{2}$, que correspondem a $17 \%$ de mata nativa. Essa subtração seria algo em torno de $11 \mathrm{mil}$ hectares, de vegetação natural por ano, sendo as áreas mais incidentes localizadas nas margens do rio São Francisco; rio Verde Grande e no perímetro de irrigação do Projeto Jaíba. Como o crescimento da malha urbana não passou de $0,04 \%$ durante esse período, esses dados confirmam que, as atividades agropecuárias, foram as principais responsáveis pela diminuição da cobertura vegetal nativa.

Os corpos hídricos também foram afetados com diminuição de aproximadamente $17,4 \mathrm{~km}^{2}$, incluídas as lagoas marginais, afluentes do rio São Francisco e do rio Verde Grande. Nos trabalhos de Oliveira (2006); Ribeiro (et. al. 2010); entre outros, estão presentes os relatos de comunidades sobre lagoas marginais e veredas que secaram ou que foi reduzido, consideravelmente, o seu volume de águas, e ainda pelo assoreamento decorrente do transporte de milhões de toneladas de solos arenosos para os leitos dos afluentes sãofranciscanos. $O$ 
assoreamento é resultado do carrilhamento de sedimentos originários das chapadas degradadas, transformadas em áreas de plantio de eucalipto e carvoejamento, apontados como um dos principais impactos ambientais acometidos na região.

Esses sistemas de produção promoveram mudanças significativas, "a agropecuária extensiva moderna modificou o manejo, pastejo e matrizes genéticas", pois a ampliação do rebanho necessitou de maiores áreas de criação de gado e plantio de capim; "a agricultura irrigada ocupou áreas de mata seca e várzeas úmidas de veredas com grandes plantios de grãos". Geralmente essas áreas mais úmidas eram ocupadas por comunidades de vazanteiros e geraizeiros que praticavam uma agricultura de autoconsumo e de baixo impacto ambiental, com interdependência das dinâmicas sãofranciscanas. O plantio de eucalipto e "o carvoejamento de mata nativa, atendia ao polo siderúrgico mineiro", muitas vezes essa última atividade destinava-se para abrir terras que seriam usadas em atividades futuras (RIBEIRO, et. al 2010, p.31).

Tais fatores contribuíram para a ampliação e concentração dos latifúndios, e no crescimento e fortalecimento de empresas rurais. O modelo gerou uma disputa por terra, território e água, revelados por diversos trabalhos que identificaram e analisaram conflitos socioambientais nos municípios em destaque. Como podem ser observados em OLIVEIRA (2006), RIBEIRO e GALIZONI (2007); RIBEIRO (et. al, 2010); BRITO 2010, FIGUEIREDO (2011), NEVES (2013), ANAYA (2014), entre outros.

As chapadas do Médio São Francisco foram privatizadas por empresas de pecuária, reflorestadoras e carvoejamento. As áreas de maior umidade, ou seja, várzeas e ou veredas foram sistematicamente drenadas, irrigadas e plantadas; as áreas de Floresta Estacional Decidual, denominadas regionalmente como Matas Secas, possuidoras de solos férteis, se transformaram em áreas de pastagens para a criação extensiva de gado. A maior parte dessas áreas já era ocupada por povos e comunidades de agricultores tradicionais, que tinham um manejo próprio, sazonal e comunal desenvolvido e repassado ao longo de gerações. Entretanto, as empresas cercavam esses espaços e ampliavam suas glebas de terras, por meio da grilagem, tornando-se uma prática frequente e, por vezes violenta. Este aspecto culminou na expropriação dos direitos de povos e comunidades tradicionais e na reorganização da estrutura fundiária (RIBEIRO, et. al. 2010).

A região Norte de Minas Gerais, até então, possuía fazendas de grande porte, mas estas não ocupavam áreas de milhares de hectares. Tinham um sistema de 
produção que não ameaçava a agricultura tradicional, e o acesso à terra se baseava em direitos consuetudinários, assemelhando-se à lógica das comunidades tradicionais. Contudo, com a modernização conservadora, veio à introdução da "grande fazenda" em moldes industrial do agribusiness, e a disseminação dos conflitos pela terra (RIBEIRO, et. al. 2010).

Com o impacto da violência no campo, não tardaram a surgir formas de luta contra a violência; à expropriação e perda dos direitos ao território tradicional. No final da década de 1970 e no decorrer dos anos 1980, motivados pelo crescimento do movimento sindical e apoio aos expropriados do campo pelas Comunidades Eclesiais de Base - CEB e Comissão Pastoral da Terra - CPT, apareceram alguns focos de resistência contra os reflexos marginalizantes da modernização do campo, porém, foi no final da década de 1990 que, os movimentos sociais começaram a tomar forma no Norte de Minas Gerais. Movimentos estes protagonizados por povos e comunidades tradicionais e dentre eles podemos destacar:

Vazanteiros em Movimento, caracteriza-se como um movimento social de reivindicação territorial, envolvendo comunidades vazanteiras e quilombolas residentes em áreas que foram sobrepostas por áreas de compensação do projeto de Projeto Jaíba, especificamente os parques estaduais Verde Grande (1998), Lagoa do Cajueiro (1998) e Mata Seca (2001), que sobrepuseram os territórios tradicionalmente ocupados. Essas terras passaram a ser consideradas prioritárias para a conservação ambiental e foram transformadas em áreas de proteção integral, desencadeando restrição às práticas vazanteiras e sua consequente expropriação por parte dos agentes ambientais do Instituto Estadual de Florestas (IEF), responsáveis pelo gerenciamento e fiscalização das unidades de conservação estaduais (ANAYA, 2014).

É importante destacar que, parte dessas terras sobrepostas pelos parques, é patrimônio da União por serem consideradas áreas de $\mathrm{LMEO}^{6}$ e denominadas pelas

\footnotetext{
${ }^{6}$ Os terrenos de marginal de rio compreendem uma faixa de 15 metros, medidos horizontalmente em direção à parte da terra, contados a partir da Linha Média das Enchentes Ordinárias (LMEO). A competência para demarcar a LMEO é da Secretaria do Patrimônio da União (SPU), por meio de procedimento administrativo e declaratório, definido no Decreto-Lei oㅜ 9.760, de 1946. Decreto № 6.040, de 7 de fevereiro de 2007, que institui a Política Nacional de Desenvolvimento Sustentável dos Povos e Comunidades Tradicionais, Estabelece como objetivo geral o desenvolvimento sustentável dos povos e comunidades tradicionais, com ênfase no reconhecimento, fortalecimento e garantia de seus diretos territoriais, sociais, ambientais, econômicos e culturais, com respeito e valorização à sua identidade, suas formas de organização e suas instituições. Tem como objetivos específicos:i) a garantia aos povos e comunidades tradicionais de seus territórios e o acesso aos recursos naturais que tradicionalmente utilizam para sua reprodução física, cultural e econômica (inciso I do artigo 3ํ); ii) a solução e/ou minimização dos conflitos gerados pela implantação de Unidades de Conservação
} 
comunidades de "Terras de Marinha". Atualmente o movimento vazanteiro, está se expandindo para uma articulação que envolve outras dezenas de comunidades vazanteiras no Médio São Francisco Mineiro com a denominação de Articulação Vazanteira.

O Movimento Geraizeiro, nasceu no Alto Rio Pardo (Norte de Minas Gerais) e se expandiu para outras áreas de domínio de cerrados e chapadas ocupadas por maciços de monocultura de eucalipto e pinus, mineração e grilagens, que em conjunto expropriaram terras comunais e intercomunitárias, utilizadas sazonalmente pelas comunidades para a "solta do gado" e como locus de recursos naturais, sendo portanto, parte integrante da reprodução do modo de vida tradicional. A identidade geraizeira está associada aos cerrados Norte Mineiros e a três unidades paisagísticas inter-relacionadas: os gerais (altiplanos e chapadas), os tabuleiros (parte intermediária) e as veredas onde se encontram os terrenos úmidos, propícios para as atividades agrícolas. Portanto, a supressão de uma dessas unidades afeta, diretamente, o modo de vida dessas comunidades (MAGALHÃES e AMORIM, 2015; DAYRELL, 1998).

No Médio São Francisco Mineiro a Comunidade do Rio dos Cochos, localizada no município de Januária, começou a se organizar no final dos anos 1990, para retomada das terras de chapadas, após a desistência das firmas no reflorestamento e plantio dos gerais. Gradativamente essas terras foram reutilizadas pela comunidade também para a "solta do gado" e animais, e para coleta de lenha e frutos (pequi, cajuzinho do campo, coquinho azedo, panã, entre outros) que, ao longo das décadas, foram se revegetando (RIBEIRO, et. al. 2010).

A organização do Movimento Geraizeiros e suas estratégias de resistência e luta, são orientadas e repensadas durante a realização de conferências que acontecem periodicamente. A mais recente, $5^{\text {a }}$ Conferência Geraizeira, ocorreu entre os dias 06 e 08 de abril de 2018, na comunidade de Catanduva, município de Vargem Grande do Rio Pardo (Minas Gerais) com o tema "Água e Território". A atividade contou com a participação de 57 comunidades geraizeiras e 577 participantes, vindos de 15 municípios da região do Alto Rio Pardo e outras partes do Norte de Minas Gerais, além de lideranças da Articulação Rosalino Gomes de

de Proteção Integral em seus territórios tradicionais e o estímulo à criação de Unidades de Conservação de Uso Sustentável (inciso II do artigo $3^{\circ}$ ); iii) garantir os direitos dos povos e das comunidades tradicionais afetados direta ou indiretamente por projetos, obras e empreendimentos: inciso IV do artigo 3‥ 
Povos e Comunidades Tradicionais e profissionais aliados de diferentes instituições da sociedade civil, de universidades e instituições de pesquisa.

Articulação Rosalino Gomes de Povos e Comunidades tradicionais é um movimento social que se constituiu formalmente no ano de 2010, na cidade de Montes Claros-MG, com a proposta de abarcar estratégias conjuntas de enfrentamento aos grupos hegemônicos, objetivando a unificação das lutas por direitos aos territórios tradicionais. Participam desta articulação os indígenas Xakriabá e Tuxá, comunidades quilombolas, geraizeiras, vazanteiras, veredeiras, caatingueiras e apanhadores de flores.

Instituições de ensino e organizações não-governamentais, vem ao longo das últimas três décadas, dando visibilidade aos movimentos sociais e povos e comunidades tradicionais, através de suas pesquisas/projetos, legitimando-os no processo de reconquista de seus territórios e reconhecimento dos seus direitos. Essas comunidades, historicamente, ainda lutam contra os antigos latifúndios. E, a partir dos anos 1990, lutam contra novos atores como os grandes conglomerados econômicos do capital agroindustrial e financeiro; mineração e siderurgia, que mantém uma relação de imposição aos rumos da questão agrária no Estado.

\section{Conclusão}

Este artigo pretendeu diagnosticar e discutir a expansão da atividade agropecuária e as consequentes mudanças no uso e ocupação do solo, subsidiada por imagens de satélite do ano 1986 e 2015, na região do Norte de Minas Gerais. O levantamento de dados e discussão acerca dos mesmos possibilitou considerar que o avanço da agropecuária no Médio São Francisco Mineiro, pautado em um modelo de modernização que privilegiou a manutenção da estrutura fundiária baseada no latifúndio, contribuiu em grande escala para a diminuição das matas nativas e dos corpos hídricos da região.

A reorganização da estrutura fundiária e os seus impactos não foram percebidos apenas no campo ambiental, mas também, no sociocultural. Os povos e comunidades tradicionais foram diretamente atingidos ao longo desse processo, por meio de violência, expropriação territorial e perda de seus direitos, comprometendo a reprodução dos seus modos de vida. Em contrapartida, a reação desses povos e comunidades foi a resistência contra os agentes hegemônicos e o capital agroindustrial, por meio da organização em movimentos sociais. 
As alterações significativas no uso e ocupação do solo nas épocas em estudo, podem ser apontadas sinteticamente: 1) Mínimo crescimento da malha urbana $(0,04 \%$ durante todo o período); 2) Avanço das atividades agropecuárias sobre as áreas de vegetação nativa, principalmente áreas localizadas às margens do rio São Francisco, rio Verde Grande e perímetro de irrigação do Projeto Jaíba. 3) Diminuição dos corpos hídricos em aproximadamente 17, 4 km²; 4) A agropecuária extensiva moderna modificou o manejo, pastejo e matrizes genéticas, pois a ampliação do rebanho necessitou de maiores áreas de criação de gado e plantio de capim, além da agricultura irrigada que ocupou áreas de mata seca e várzeas úmidas de veredas com plantios de grãos e ou plantio de eucalipto nas chapadas. Tais fatores contribuíram para a ampliação e concentração dos latifúndios, e no crescimento e fortalecimento de empresas rurais. A maior parte dessas áreas impactadas já era outrora ocupada por povos e comunidades de agricultores tradicionais.

A perspectiva do uso e apropriação de territórios pelos agentes hegemônicos, nas épocas em estudo, dão visibilidade aos conflitos socioambientais com as comunidades e povos tradicionais, diretamente afetados pelos grandes empreendimentos na região. Sejam estes empreendimentos preservacionistas/conservacionistas, delimitados por áreas de proteção ambiental, ou dados pela expansão agropecuária, mineração e outros. Há sobretudo, a partir da década de 1980, um contínuo fortalecimento de ações contrárias, impressas nos movimentos sociais de resistência que atualmente, são expressivos na região.

O cerceamento dos povos e comunidades tradicionais, em acessar os recursos naturais e os territórios que são componentes integrantes do seus modos de vida, imposto pelo novo modelo agrícola oriundo da revolução verde, trazem outras questões a serem pensadas, que dizem respeito a relação das políticas desenvolvimentistas e as questões socioambientais pois, enquanto os projetos desenvolvimentistas têm a terra, a água e as florestas como possibilidade de exploração e produção de lucro, os povos e comunidades tradicionais as tem como, espaço de reprodução social, afeto e trabalho, a perspectiva, portanto não é de dominação da natureza mas sim, de convivência harmônica e horizontal. Os processos de resistência emergentes são pelo direito a vida e não somente a terra.

Este estudo não pretende encerrar a discussão sobre o assunto em pauta, mas permite apontar outros caminhos que podem ser explorados pela cartografia e suas tecnologias. O mesmo pode subsidiar estudos que possibilitem análises de 
marcos temporais distintos, envolvendo povos e comunidades tradicionais diretamente impactadas pelo avanço das atividades provenientes do agronegócio. Podendo possibilitar ainda, o apontamento das modificações espaciais de ações passadas e presentes que se materializam no espaço geográfico.

\section{REFERÊNCIAS}

ABRAMOVAY, R. Paradigmas do capitalismo agrário em questão. - $3^{\circ}$ Ed.- São Paulo EDUSP, 2007.

ANAYA, F. C.. "Vazanteiros em movimento": o processo de ambientalização de suas lutas territoriais no contexto das políticas de modernização ecológica. Ciências \& Saúde Coletiva, 19(10):4041-4050, 2014.

ANAYA, Felisa; BARBOSA, R. S.; SAMPAIO, C. Sociedade e Biodiversidade na Mata Seca Mineira. UNIMONTES CIENTÍFICA, Montes Claros v.8, n.1 - jan./jun. 2006.

ARAÚJO, Elisa Cotta. Nas margens do São Francisco: sociodinâmicas ambientais, expropriação territorial e afirmação étnica do quilombo da lapinha e dos vazanteiros do Pau de Légua. Dissertação (Mestrado), Montes Claros: PPGDS/ Unimontes: 2009.

BARBOSA, R. S.; FEITOSA, A M. A dinâmica de luta pela terra no norte de Minas Gerais. em J. Cleps Júnior, J. A. Zuba, A. M. Feitosa (Orgs.). (2005). "Debaixo da Lona:

tendências e desafios regionais da luta pela posse da terra e da reforma agrária no Brasil”. Goiânia-GO. Editora da UCG.

BRANDÃO, C.R.; LEAL, A. Comunidade Tradicional: conviver, criar resistir. Revista da ANPEGE, v. 8, n. 09, p. 73-91, 2012.

BRITO, Isabel C. B. de; A Rede-Movimento dos Geraizeiros do norte de Minas. VI encontro Nacional da Anppas, 18 - 21 de setembro, Belém- PA, 2012.

CÂMARA, G, SOUZA, R.C.M, FREITAS, U.M, GARRIDO, J. SPRING: Integrating remote sensing and GIS by object-oriented data modelling. Computers \& Graphics, v. 20, n. 3, p. 395-403, 1996.

COSTA, J. B. Cerrados Norte Mineiros: populações tradicionais e suas identidades territoriais. In: ALMEIDA, Maria Geralda de. (org.). Tantos Cerrados - Múltiplas abordagens sobre a biodiversidade e singularidade cultural. Goiânia: Ed. Vieira, 2005.

DAYRELL, C. Geraizeiros e Biodiversidade no Norte de Minas: a contribuição da agroecologia e da etnoecologia nos estudos dos agroecossistemas tradicionais. Dissertação (Maestria em Agroecologia y Desarrollo Rural Sostenible) - Universidade Internacional de Andalucia, Sede Ibero Americana de La Rábida, Huelva, Espanha, 1998.

DAYRELL, C. Rebeldia nos sertões. Agriculturas, v. 8, n. 4,p. 10-14, dez. 2011.

ESRI. ArcGis 10.2. Redland, California. Software. 2013.

FIGUEIREDO, L. V. R. Percepção Ambiental em uma Unidade de Conservação de Proteção Integral. Dissertação (Mestrado), Montes Claros: PPGDS/ Unimontes: 2011. 
IBGE, Instituto Brasileiro de Geografia e Estatística. Evolução municipal. Disponível em: $<\mathrm{ftp} / / / \mathrm{ftp}$. ibge.gov.br/Cartas_e_Mapas/Mapas_Tematicos/>. Acessado em: $15 \mathrm{de}$ mar. de 2016.

INPE, Instituto Nacional de Pesquisas Espaciais. Catálogo de imagens. Disponível em: <http://www.dgi.inpe.br/CDSR/>. Acessado em: 15 de mar. de 2016.

JESUS, S. M. de. Planejamento, gestão e ordenamento territorial no médio São Francisco no Norte de Minas Gerais. Dissertação (mestrado) - Programa de PósGraduação em Desenvolvimento Social, Universidade Estadual de Montes Claros Unimontes/PPGDS, 2009.

MAGALHÃES, F.R. de; AMORIM, R. de A., O Movimento dos Geraizeiros e a Luta Pela Terra no Alto Rio Pardo. RURIS, vol. 9, n. 2 set/2015.

PONZONI, F. J.; REZENDE, A. C. P. Influência da resolução espacial de imagens orbitais na identificação de elementos da paisagem em Altamira-PA. Revista Árvore, v. 26, n. 4, p. 403-410, 2002.

RIBEIRO, E. M.; e GALIZONI, F. M. Quatro Histórias de Terras Perdidas: Modernização Agrária e Privatização de Campos Comuns em Minas Gerais. R. B. Estudos Urbanos e Regionais.V. 9, N.2 / Novembro, 2007.

RODRIGUES, T.W.P,; GUIMARÃES, U.S.; ROTTA, L.H.S.; WATANABE, F.S.Y.;

ALCANTARA, E.; IMAI, N.N. Delineamento amostral em reservatórios utilizando imagens Landsat-8/OLI: um estudo de caso no reservatório de Nova Avanhandava (Estado de São Paulo, Brasil). Boletim de Ciências Geodésicas, v. 22, n. 2, p. 303-323, 2016.

NEVES, S. L. S.. Dos saberes tradicionais à agroecologia: um estudo de caso das práticas agrícolas da comunidade vazanteira da llha do Jenipapo, Itacarambi-MG. Rev. Bras. de Agroecologia. 8(2): 44-61 (2013).

SILVA, A.B. Técnicas de segmentação de imagens e classificação por região: mapeamento da cobertura vegetal e uso do solo, Mucugê-BA. Mercator, v. 8, n. 17, p. 209-220, 2009.

\section{SÍTIOS CONSULTADOS:}

https://racismoambiental.net.br/2016/02/11/rebeldia-nos-sertoes-por-carlos-alberto-dayrell-2/ acesso em 13 de junho de 2018.

https://www.caa.org.br/biblioteca/noticia/5-conferencia-geraizeira acesso em 15 de agosto de 2018.

https://www.facebook.com/Articula\%C3\%A7\%C3\%A3o-Rosalino-Gomes-669537689899667/ acesso em 15 de agosto de 2018.

\section{NOTAS DE AUTOR}

\section{CONTRIBUIÇÃO DE AUTORIA}

Sérgio Leandro Sousa Neves - Concepção. Coleta de dados, Análise de dados, Elaboração do manuscrito, revisão e aprovação da versão final do trabalho

Marcos Esdras Leite - Análise de dados, Elaboração de mapas, revisão e aprovação da versão final do trabalho Lisa Vany Ribeiro Figueiredo Neves - Análise de dados, Elaboração de mapas, revisão e aprovação da versão final do trabalho

\section{FINANCIAMENTO}

Bolsa de incentivo a pesquisa da Fundação de Aparo a Pesquisa de Minas Gerais - FAPEMIG. 
APROVAÇÃO DE COMITÊ DE ÉTICA EM PESQUISA

Não se aplica

\section{CONFLITO DE INTERESSES}

Não se aplica

\section{LICENÇA DE USO}

Este artigo está licenciado sob a Licença Creative Commons CC-BY. Com essa licença você pode compartilhar, adaptar, criar para qualquer fim, desde que atribua a autoria da obra.

\section{HISTÓRICO}

Recebido em: 10-02-2019

Aprovado em: 17-10-2019 